\title{
Jawi using multi-maker augmented reality
}

\author{
Siti Hasnah Tanalol ${ }^{1}$, Dinna N. Mohd Nizam² ${ }^{2}$ Zaidatol Haslinda Abdullah Sani ${ }^{3}$, Aslina Baharum ${ }^{4}$, \\ Asni Tahir ${ }^{5}$, Iznora Aini Zolkifly ${ }^{6}$ \\ 1,2,3,4,5 UX Research Lab, Faculty of Computing and Informatics, Universiti Malaysia Sabah, Malaysia \\ ${ }^{6}$ Department Faculty of Business and Information Technology, UNITAR International University, Malaysia
}

\begin{abstract}
Article Info
Article history:

Received Apr 8, 2020

Revised Jul 14, 2020

Accepted Aug 18, 2021

\section{Keywords:}

Augmented reality

Electroencephalography

Gamification

Jawi

ABSTRACT

This paper discussed the development of multi-maker augmented reality for learning Jawi in order to complement the formal study in school. We conducted an experiment with $\mathrm{N}=10$ participants from Pusat Minda Lestari, UMS age 5 and 6 years old, to study the effectiveness of learning Jawi using the developed mobile augmented reality application. We prepared a test environment comprising an electroencephalography (EEG) system and mobile augmented reality (AR) application for analysis and testing. Results found that the learn ability of the students was improved after they used the mobile application to learn basic Jawi. The methodology used was ADDIE model, which included the analysis, design, development, implementation, and evaluate phases. This project is an innovation in learning Jawi and hopefully can increase the children's interest in learning Jawi.
\end{abstract}

Multi-marker

This is an open access article under the CC BY-SA license.

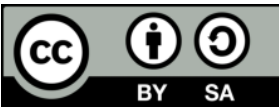

Corresponding Author:

Aslina Baharum

UXRL, Faculty of Computing and Informatics

University Malaysia Sabah

Jalan UMS, 88400 Kota Kinabalu, Sabah, Malaysia

Email: hasnah@ums.edu.my

\section{INTRODUCTION}

Augmented reality (AR) offers us with so many opportunities for teaching and learning. AR allows us to interact with the physical world around us [1] while the understanding is enhanced [2] through the addition of digital content that is overlayed on that physical world. This additional content included information that is helpful for an extended experience in learning [3], such as video and directional guidance. A Jawi script is one of the world's oldest scripting [4]. Though, Jawi scripting has getting unrecognized by the younger generations [5]. Nevertheless, reading Jawi script is still important and relevant as the skill is required when reading al-Qur'an, learning Arabic languages and other Islamic subjects in Malaysian school. The application of AR could attract students to learn Jawi alphabets using mobile phone, anywhere, anytime.

Jawi script is considered as the heritage of the Malay people and therefore preserving and maintaining the script is essential because it shapes of the Malays cultural heritage and their identity. Jawi scripting system has played a vital role not only as a medium to spread the Islamic teaching but also the advancement of the cultural and language [6]. Towards the end of $20^{\text {th }}$ century, Jawi script slowly has faded away as it is increasingly replaced by Rumi (Roman alphabets). The usage of Rumi in the education system causing the younger Malay generations is no longer able to read Jawi script fluently.

Nevertheless, Jawi script is still used as the medium for teaching and learning of Islamic studies, a compulsory subject in Malaysia school for the Malays. The limited allocation of time to learn and practice Jawi writing in school is causing students hard to master writing and reading in Jawi [7]. Besides that, student's incompetence in the context of issues refers to the basic skills of reading, writing and spelling Jawi. 
There are spelling error in Jawi writing among students dictated from the misuse of proper Jawi spelling, letters, sentences, and spelling laws [8]. Though, Jawi writing system has no longer widely used as a medium of writing in Malaysia. As a result, the ability of Malaysian students to master in Jawi reading and writing skills is reported as not satisfying. Soon, the younger generation will ignore this Malay heritage. According to [9] research stated that in order to master Jawi writing is not simply easy like other language writing skills. It requires cognitive and psychomotor abilities, competence and progress of perfect senses to forming and produce the Jawi shapes besides requires coordination of eye and brain [10]. This is because Jawi writing is an art that need to be taught by correct ways and technique from the beginning. Furthermore, student's that weak in Jawi stemmed by their socio-economic factor. The current generation of students prefers more interactive ways in learning as the development of software apps for mobile devices becoming quite famous especially in recent years [11], [12]. Jawi writing is very important in Islamic education system. Jawi has been used by Islamic education teachers in primary and secondary school. Unfortunately, there is lack of interest among the school children to learn Jawi and many of them nowadays are unable to read and write in Jawi [13]. In order to gain interest in learning Jawi, an interactive and interesting application [14] should be develop so that it can attract them to learn Jawi. Thus, a mobile application for learning Jawi will be develop as an alternative learning tool. This application is built to motivate the students to learn and improve their knowledge about Jawi as well as read the correct pronunciations of each Jawi alphabet. This application also provides module showing how to connect each alphabet and shows the user how to read sentences in Jawi.

One of the significant developing technologies for visualization purpose is AR which can be applied to computers, tablets and smartphones. AR affords the ability to overlay images, text, video and audio components onto existing images or space [6]. There are many applications been developed in order to improve educational learning that applies AR functions that used to attract younger generations [15]. Augmented reality has the potential to improve the new method of education medium [16] including learning Jawi script. Therefore, augmented reality allows educator to "re-conceptualize" of how they view learning and "re-think" what they should teach by engaging technology [17] to view aspects of the real world in different way [18]. In education, AR has the potential to make ubiquitous learning a reality [19], allowing learners to gain immediate access to a wide range of information from various sources [20]. Research in conceptual learning in immersive augmented scene has recently seen a great progress. AR technology can be utilized through a variety of mediums including desktops, mobile devices and smartphones. The technology is portable and adaptable to a variety of scenarios. When using AR outside of classroom, teachers and students are able to use this as a tool for physical activity [21].

“Augmented Reality for Learning Jawi" is an enhancement from existing learning method. Most of the existing learning methods were using traditional methods such as books and CDs. This application was developed with an additional gamification module for user besides the combination of the 2D, 3D animation and audio. When the student scan at the alphabet marker on the flash card, the 3D graphic of the relevant animal and its Jawi alphabet will popped-out. The students able to interact with the 3D object and shown the video on the correct way to write Jawi alphabets.

\section{METHODOLOGY}

This project is using an "ADDIE methodology" in developing the application. The reason of using this method is because it can be used to develop this interactive application. It consists of step by step of what [18] will be done throughout the development of the application. "ADDIE Methodology" have five phase consists of analysis, design, development, implementation, and evaluation. Figure 1 shows the ADDIE model that consists of analysis, design, development, implement and evaluate phases.

\subsection{Analysis}

In this phase, research was done to identify the goals, purpose, objective, audience, identify content and instruct the strategies. After the analysis has been done, the goal has been set to develop a new way of learning Jawi by using multi-marker augmented reality which will include 2D, 3D animation and audio in order to attract user's interest. The multi-marker technique is used to combine two different markers to display the combined Jawi alphabets. The content of "Augmented Reality for Jawi Alphabets" are based on revision and research with the other learning Jawi with common and traditional method of learning using book and $\mathrm{CD}$. The target audience for this project is kid age of five to nine. The scope of the mobile application covers several modules; learn how to recognize the Jawi alphabets, learn how to pronounce it correctly, learn how to combine two Jawi alphabets together and quizzes with gamification element.

\subsection{Design}

After completing the analysis phase, the developer identified the possible task need to be done while develop the application. Developer did the overall analysis about the planning and project flow. In this phase, 
drafts of the interface design and the mobile application environment were focused on the school children that suit the children where it should be more attractive and interactive. The font size and the buttons must be easy for the user to read and use. The design must be user friendly. It must consider several aspects that related to Jawi learning such as the matching of Jawi alphabets with the ABC alphabets, so that the user knows how to convert Jawi alphabets into ABC alphabets and vice versa. Figure 2 shows the example of matching of Jawi alphabets with the ABC alphabets.

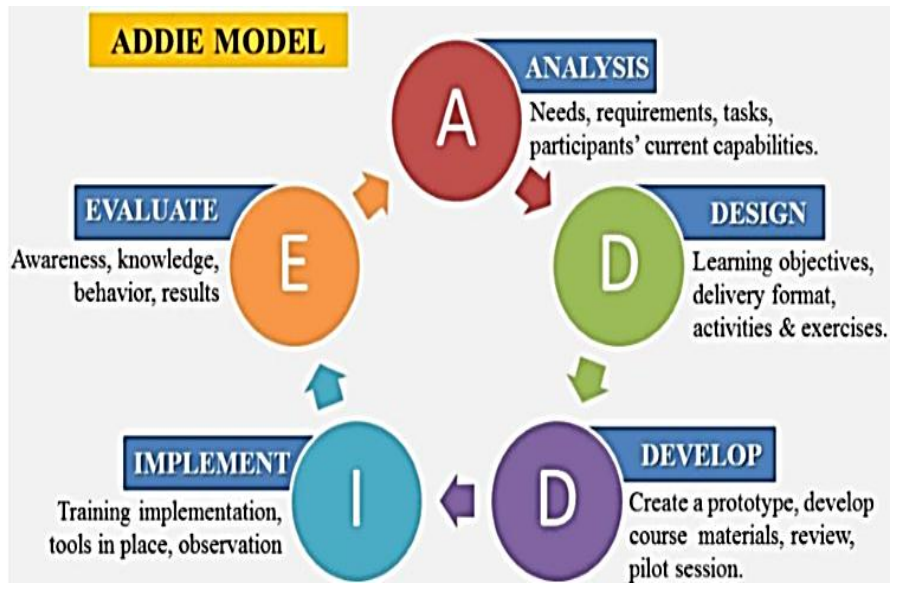

Figure 1. ADDIE model

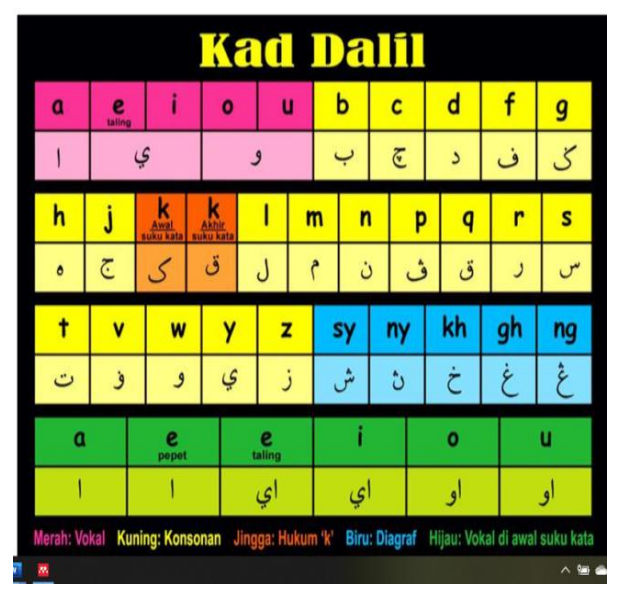

Figure 2. Kad Dalil

\subsection{Development}

In this phase, the developer starts to build the product based on the first two phase. Here developer starts making a 3D alphabet in 3D software. This based on the content that has been sketch on design phase. The developer needed to complete at least $80 \%$ complete prototype to ensure the project are working as time required and needed. In this phase, all the problems must be solved, and the prototype can be used as final product.

\subsection{Implementation}

All the interfaces are put into action, integrated with the AR and gamification modules based on the requirements needed. The integration of multi-marker for Jawi alphabets was done in the Unity3D software using C\# programming and Vuforia.

\subsection{Evaluation}

During this phase, the completed product was tested by the school children from Pusat Minda Lestari Kindergarten. The product is being measured on how well it achieved its goals using the EEG.

\section{MOBILE AUGMENTED REALITY FOR LEARNING JAWI}

Jawi AR consists of three main modules: Learning Jawi, quizzes using gamification concept and AR module. The modules provided in the mobile applications are as in Figure 3. Some interfaces of the Jawi AR mobile applications are shown in Figure 4.

\subsection{Marker design}

AR requires marker detector to mark the Jawi flashcards and display the 3D Jawi alphabets. In order to ensure good performance of the marker detector perform best when used on rich and highly textured images. Having bold line or block design caused image will have less recognizable local regions, therefore detection will have affected poor performance. In development of this application, the marker images were designed and stored in Vuforia database for developer. Figure 5 describes three stages of marker recognition process. It is start with process image conversion, compute feature point and end with identification process. 


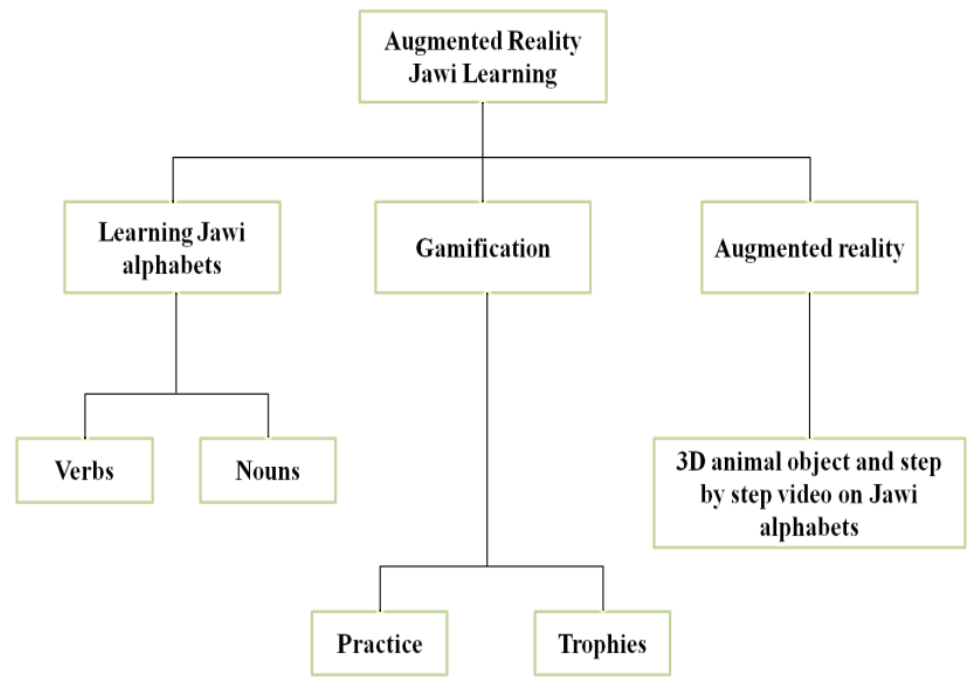

Figure 3. Overview of the mobile application of AR Jawi learning
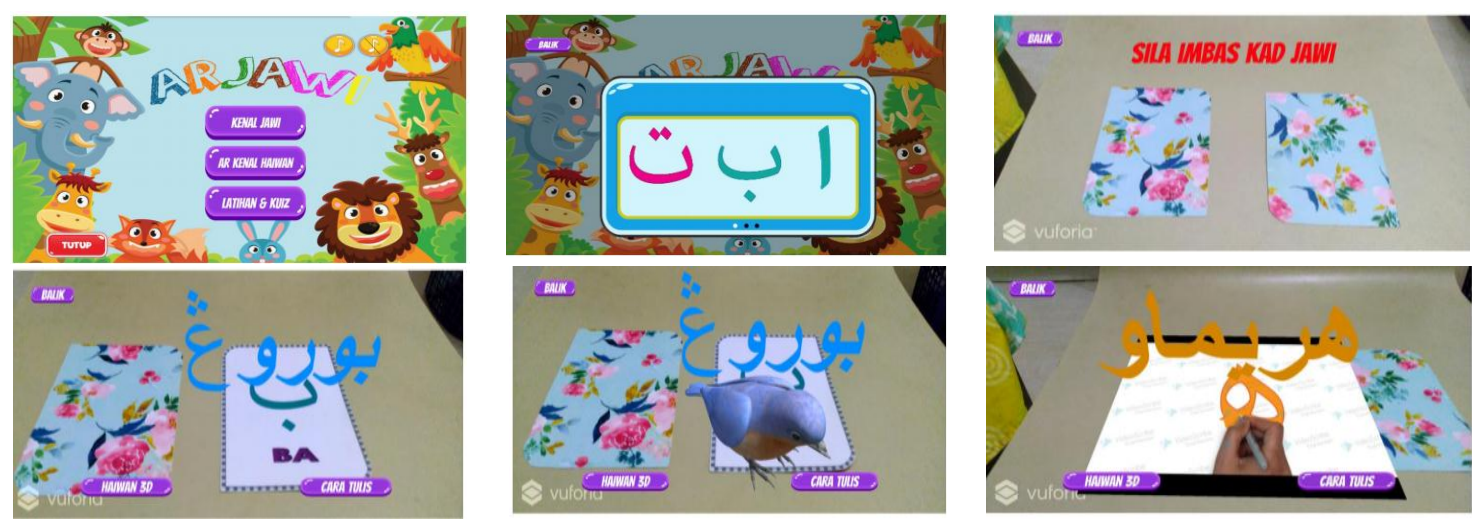

Figure 4. Interfaces of Jawi AR

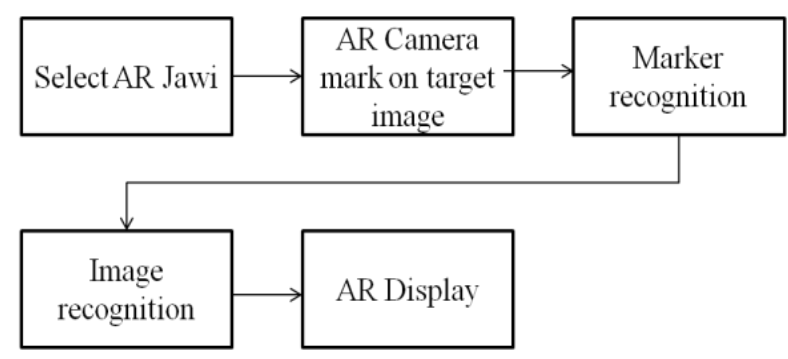

Figure 5. Marker recognition process of augmented reality

\section{LEARNABILITY TESTING}

The electrochemical signal in human's brain is produced and processed when we see through the vision sensor. These signals are known as brainwaves. With the rhythmic characteristic made it possible to be measured using electroencephalography (EEG) [22]. Brainwaves are always present as a variety of sinusoidal EEG activity, changing when mental and physical state of subject changes [10]. The brain waves spectrums are divided into specific frequencies range. EEG enables non-invasive observation of electrical processes inside cerebral cortex, which is believed to be responsible for our individual thoughts, emotions and behaviors [11]. Besides, EEG also able to capture and monitor the changes of emotions based on one's brainwaves pattern [23]. Furthermore, [24] explain that the central nervous system's activity initiated by information processing can be measured by EEG. Therefore, the level of learnability could be identified 
using EEG [23], [25] while learning Jawi using the mobile application. The testing undergoes by observation techniques based on user learnability using the AR Jawi mobile application. The testing was done by observation, shown in Figure 6, which involves studying users with a little control of user's activities and analysis using the EEG, involving 12 respondents age 5 and 6 years old from Tadika Pusat Minda Lestari (PML), UMS.
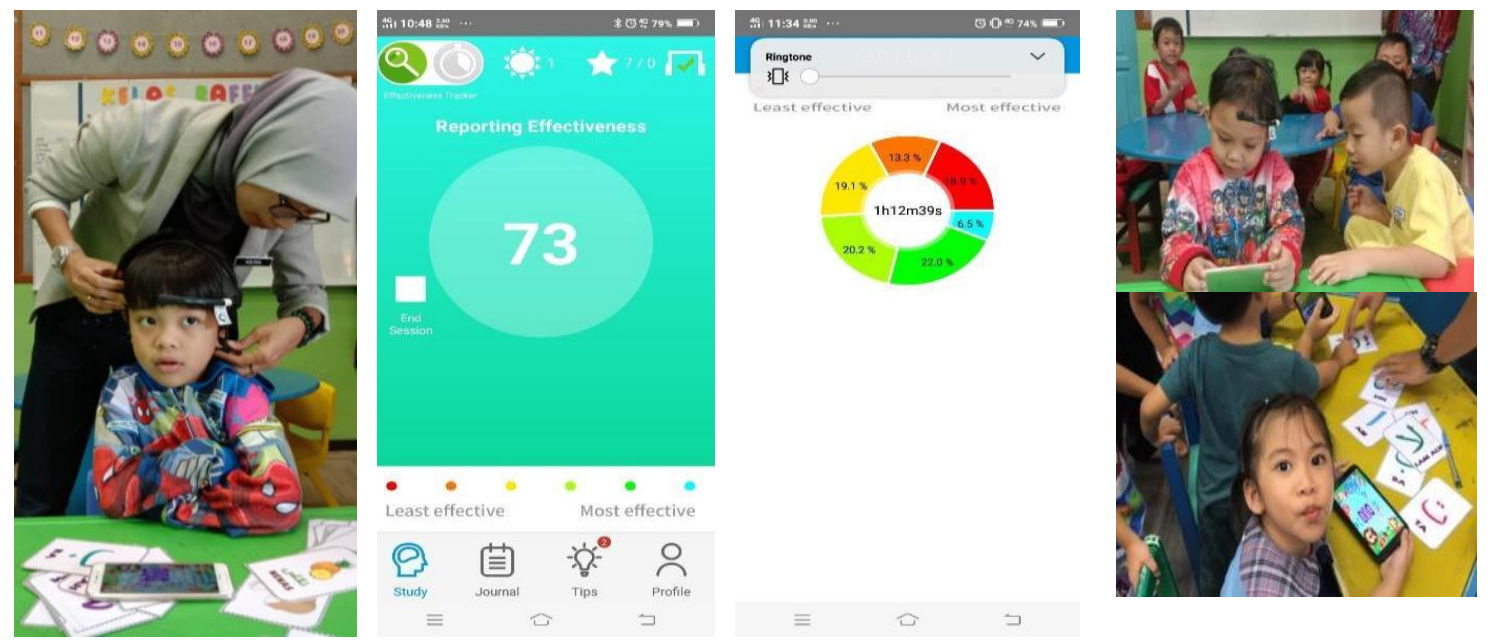

Figure 6. Observation on AR Jawi application testing on user acceptance to learn the functions of the mobile application using EEG

Table 1 shows the EEG device score for PML pre-school students. The score of the EEG device for less than 5 minutes indicate that almost $55.6 \%$ of effectiveness in children was taken from 3 children only. This then shows a slight decrease to $46.5 \%$ when the period is more than 5 minutes, were taken from 9 children. The result followed the prediction of the result in phase one where the effectiveness in learning will be decreasing to time. Even though, the level of high percentage of effectiveness reaches more than 55.6\% which shows that the mobile learning application in this area was rather effective.

Table 1. EEG device score for PML

\begin{tabular}{ccccccc}
\hline Minute & & No & Minimum & Maximum & Mean & Std. deviation \\
\hline$<5$ mins & Time (mm:ss) & 3 & $2: 56$ & $4: 20$ & $3: 44$ & $0: 03$ \\
& Percentage (\%) & 3 & 32.7 & 77.7 & 55.6 & 23.6 \\
$>5$ mins & Time (mm:ss) & 9 & $5: 27$ & $9: 25$ & $6: 56$ & $0: 05$ \\
& Percentage (\%) & 9 & 14.9 & 86.0 & 46.5 & 25.2 \\
\hline
\end{tabular}

\section{CONCLUSION}

"Augmented Reality for Jawi Alphabets" is suitable to use among kids to gain knowledge and information and learn about Jawi. It is user friendly since it is easy to use by kids and adults. The user only needs to scan at the Jawi alphabet marker then the words will appear on to the screen. Besides, it also can be an indoor activity for a family to gain knowledge and do the interactive learning. Therefore, this kind of learning will encourage the children to become more excited to learn Jawi. This project has a potential to grow more in the future. Other learning features can be added in this project such as learning how to write Jawi alphabets, learn to read Jawi in long sentences for example in one paragraph. Based on the result, the evaluation of learn ability conducted, using mobile augmented reality application able to assist and attract the kids to learn Jawi.

\section{REFERENCES}

[1] Feng Zhou, H. B. Duh, and M. Billinghurst, "Trends in augmented reality tracking, interaction and display: A review of ten years of ISMAR," 2008 7th IEEE/ACM International Symposium on Mixed and Augmented Reality, 2008, pp. 193-202, doi: 10.1109/ISMAR.2008.4637362. 
[2] N. A. Abd. Majid, “Application of mobile augmented reality in a computer science course," International Visual Informatics Conference, Springer, Cham, pp. 516-525, 2013, doi: 10.1007/978-3-319-02958-0_47.

[3] P. Malliga, S. Senthilvel, S. Preethi, and S. Sadhana Routh, "Enchancing learning experience through augmented reality," SSRN Electronic Journal, pp. 1-9, 2019, doi: 10.2139/ssrn.3377597.

[4] A. Hj Ab Rahman, A. M. Ali, F. Abdullah, F. Khairi A. Kadir, F. Adam, and D. Ismail, "Methods of learning and writing Jawi scripts within the malay community: Past and present experiences," Proceedings of ISER $70^{\text {th }}$ Ineternational conference, vol. 3, no. 10, pp. 6-12, 2017.

[5] K. Salehuddin, "Penilaian ke atas Kerumitan Kognitif dalam Proses Membaca Jawi," GEMA Online Journal of Language Studies, vol. 12, no. 4, pp. 1179-1192, 2012

[6] A. Ismail, "Penguasaan tulisan Jawi di kalangan pelajar UPM," PhD dissertation, Univeristi Putra Malaysia, 2000.

[7] Rohaya Abd Rashid, "Tahap Penguasaan Murid Tahun 3 Dalam Menjawikan Perkataan Menggunakan Modul Kem Cemerlang Jawi,” Disertation, Universiti Sains Islam Malaysia, 2016.

[8] Ahmad Faisal Abdul Hamid, and Faizuri Abdul Latif, "Sejarah Perkembangan Tulisan Jawi: Analisis Mengenai Teori Kang Kyoung Seok (Historical Development of Jawi Script: Analysis to Theory of Kang Kyoung Seok)," Jurnal Al-Tamaddun, vol. 9, no. 2, pp. 1-15, 2014.

[9] M. F. Mohamed, S. M. Enam, M. A. Zailani, S. K. S. Ali, and Wail Ismail "The influence of teaching practice and students' attitude to the level of ability in writing Jawi script," International Journal of Multidisciplinary Education and Research-IJMER, vol. 2, no. 2, pp. 32-36, 2015, doi: 10.15224/978-1-63248-046-0-68.

[10] N. Mat Diah and N. A. Mat Zin, "Digital training tool framework for jawi character formation," International Visual Informatics Conference, Springer, Berlin, vol. 7066, no. 2011, pp. 164-175, 2011, doi: 10.1007/978-3-64225191-7_16.

[11] F. Bara and E. Gentaz, "Haptics in teaching handwriting: The role of perceptual and visuo-motor skills," Human Movement Science, vol. 30, no. 4, pp. 745-59, 2011, doi: 10.1016/j.humov.2010.05.015

[12] M. M. Amin, H. B. Zaman and A. Ahmad, "Visual haptic approach complements learning process of Jawi handwriting skills," 2013 5th International Conference on Information and Communication Technology for the Muslim World (ICT4M), 2013, pp. 1-6, doi: 10.1109/ICT4M.2013.6518888.

[13] N. Mat Diah, M. Ismail, P. M. A. Hamid, and S. Ahmad, "A development of a computer-assisted software (AJaW) that encourages Jawi writing for children," Journal Education, vol 2, no. 5, pp. 130-135, 2012, doi: 10.5923/j.edu.20120205.04.

[14] A. Baharum, M. Chai, S. H. Tanalol, N. H. Zain, M. N. Zulhemay, E. A. Rahim, and M. Omar, "Stress monitoring using mobile phone and wearable technology: Stress catcher," Journal of Telecommunication, Electronic and Computer Engineering, vol. 9, no. 2-3, pp. 21-26, 2017.

[15] R. A. Ghani, M. S. Zakaria and K. Omar, "Jawi-Malay transliteration," 2009 International Conference on Electrical Engineering and Informatics, 2009, pp. 154-157, doi: 10.1109/ICEEI.2009.5254799.

[16] A. Baharum, L. Y. Wan, F. Yahya, N. H. Nazlah, N. A. M. Noh, I. Ismail, and N. A. M. Noor, "Mobile learning application: Flipped classroom," Indonesian Journal of Electrical Engineering and Computer Science, vol. 17, no. 2, pp. 1084-1090. 2019, doi: 10.11591/ijeecs.v17.i2.pp1084-1090.

[17] M. Dunleavy and C. Dede, "Augmented reality teaching and learning," Handbook of Research on Educational Communications and Technology: Fourth Edition. Springer New York, pp. 735-745, 2014, doi: 10.1007/978-14614-3185-5_59.

[18] M. B. Báñez, Á. Di Serio, D. Villarán, and C. Delgado Kloos, "Experimenting with electromagnetism using augmented reality: Impact on flow student experience and educational effectiveness," Computers and Education, vol. 71, pp. 1-13, 2014, doi: 10.1016/j.compedu.2013.09.004.

[19] T. Thornton, J. V. Ernst, and A. C. Clark, "Augmented reality as a Visual and Spatial Learning Tool in Technology education: Potential Exists for AR to Be Incorporated in Not Only STEM Education, but across All Disciplines," The Journal of Technology and Engineering Teacher, vol. 71, no. 8, pp. 18-21, 2012.

[20] M. Antonioli, C. Blake, and K. Sparks, "Augmented reality applications in education," The Journal of Technology Studies, vol. 40, no. 1/2, pp. 96-107, 2014.

[21] L. Sanchez, V. Gutierrez, J. A. Galache, P. Sotres, J. R. Santana, and L. Muñoz, "Engaging individuals in the smart city paradigm: Participatory sensing and augmented reality," Interdisciplinary Studies Journal, vol. 3, no. 4, pp. 113, 2014.

[22] B. Aras, "Augmented reality with mobile and ubiquitous learning: Immersive, enriched, situated, and seamless learning experiences," Digital Tools for Seamless Learning, IGI Global, pp. 27-41, 2017, doi: 10.4018/978-1-52251692-7.ch002.

[23] A. M. Kamarainen, S. Metcalf, T. Grotzer, A. Browne, D. Mazzuca, M. S. Tutwiler, and C. Dede, "EcoMOBILE: Integrating augmented reality and probeware with environmental education field trips," Computers and Education, vol. 68, pp. 545-556, 2013, doi: 10.1016/j.compedu.2013.02.018.

[24] L. R. Squire, "Encyclopedia of learning and memory," Choice Reviews Online (1993), vol. 30, no. 08, pp. 30-415030-4150, 1993.

[25] M. Gasah, A. Baharum, and N. H. M. Zain, "Measure learning effectiveness among children using EEG device and mobile application," Indonesian Journal of Electrical Engineering and Computer Science IJEECS), vol. 17, no. 1, pp. 191-196, 2019, doi: 10.11591/ijeecs.v17.i1.pp191-196. 


\section{BIOGRAPHIES OF AUTHORS}
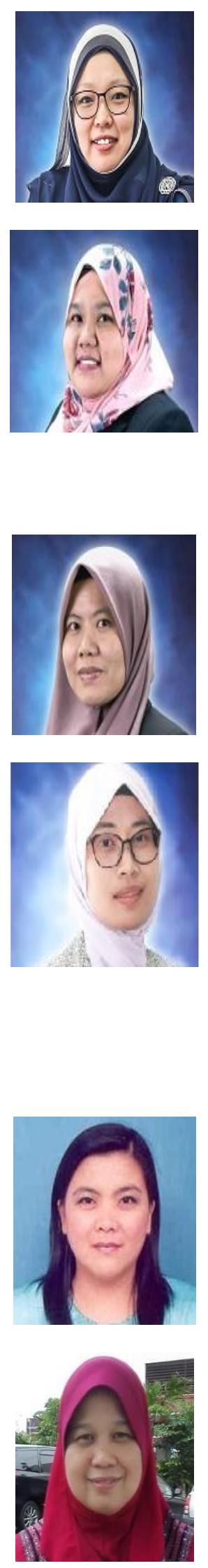

Siti Hasnah Tanalol currently works at the Faculty of Computing and Informatics, Universiti Malaysia Sabah (UMS) as a senior lecturer. Her research interest is in Computing in Mathematics, real time Computer Graphics, augmented reality application and user experience (UX). She currently holds and involves several research grants as a project leader and coresearcher. Her team has won several gold medals in innovation competitions. Siti is also the instructor for Cisco Networking Academy Program, as well as the Huawei Certification Networking Academy.

Dinna Nina Mohd Nizam received her PhD (Computer Science) from the University of Leicester (UK) last year, 2019. She completed her Bachelor of Information Technology (System Management) from Universiti Malaysia Sabah in 2001 and her Masters of Electronic Commerce (Technology) from the University of Wollongong (Australia) in 2005. She is currently a Senior Lecturer with the Faculty of Computing and Informatics in University Malaysia Sabah. During her tenure as a PhD student, she was involved under the Interaction Design and Evaluation of Socio-technical Systems (IDEAS) research group that primarily focused on usability and user experience studies. Her PhD focused on young children involving digital games and eye-tracking technology. She currently holds and involves several research grants as a project leader and co-researcher. Her interest is Human-Computer Interaction, Gamification, Usability, User Experience, Eye-tracking and Machine Learning.

Zaidatol Haslinda Abdullah Sani received her $\mathrm{PhD}$ in Computer Science from the University of York, United Kingdom. She completed her Master in Information Technology and Bachelor of Computing from the University of Tasmania, Australia. Currently, she is a senior lecturer at the Faculty of Computing and Informatics, Universiti Malaysia Sabah (UMS). She is actively conducting research and holds a grant as the project leader. She is also a member of other grants as well. Her research interest involved in special-needs, user experience, and usability studies.

Ts. Dr. Aslina Baharum is a senior lecturer at the Faculty of Computing and Informatics, Universiti Malaysia Sabah (UMS). Hold and has actively involved several grants as project leader and co-researcher. Active in community services and won several medals (>30) award in research and innovation, awarded several publications, teaching, Excellence Service, and UMS Researchers awards. Has co-authored and published several books, book of chapters, technical papers and indexed journals $(>40)$ papers. Served as editor for several journals, and scholarly contributed as committee and chairs session for conferences, editorial team and manuscript reviewers. Her research interests are in Human-Computer Interaction (HCI), Visual Informatics, Multimedia, User Experience (UX), Mental Model, Software Engineering, ICT, E-Commerce, and Entrepreneurship. She is currently an active member of ACM, IEEE, IACSIT, ICSES, Royal Institute of Information Technology (Fellow), UACEE, the IRED, and the SAI. Certified Professional Entrepreneurial Educator and Executive Entrepreneurial Leaders.

Asni Tahir is a lecturer at the Faculty of Computing \& Informatics, Universiti Malaysia Sabah in Malaysia. Her research interest includes adaptive educational hypermedia system, WSN and the use of augmented reality in indigenous language learning. She is also involves in a few research grants as a leader and co-researcher to the research that interest her. When she is not doing all that, she loves to read and try new things. And in order to distress she loves joining running event (on the road \& trail).

Iznora Aini Zolkifly is a Senior Lecturer from University of Management and Technology (formaly known as UNITAR Pintar Campus). She obtained her master degree (MIT(Comp.Science) from UKM in 2000.Currently she is working in predictive collision avoidance algorithm for virtual environment. Her interest included optimization algorithms, motion planning in crowd simulation and human computer interaction. 